\title{
Guest-editorial
}

\section{Special issue on networked learner support}

Many new challenges and opportunities are emerging at present for providers of end-user training and help in the use of electronic information resources. Technological developments, changing user needs and new models for both campusbased and distance learning, combined in the UK with the recommendations of the Follett and Fielden reports [1,2], make it both timely and necessary for information professionals to focus on the ways learners are supported within the electronic environment. Increasingly, teaching, learning and research are being carried out across the networks - and the characteristic which distinguishes networked learning from previous forms of computer-based learning is the use of computermediated communications (CMC) technologies to facilitate learner interactions. No longer do learners simply access on-line learning resources and interact with a system; they can take part in on-line discussions and communicate with peers, tutors and, of course, information professionals by means of CMC. User education, information skills training, and general advisory help can all be carried out in the networked space, and currently we are seeing services offering both easily accessible networked open learning materials and adopting other strategies which take advantage of the potential for one-to-one and one-to-many interactions using CMC. We have adopted the term "networked learner support" (NLS) to describe these activities, and this is the focus for this special issue of Education for Information [3].

Although the discussion here is about NLS in higher education, the application of NLS principles and practices is much broader and is appropriate to information professionals working in almost any setting. As organisational intranets become more widespread, managing the information contained within these systems and ensuring that users are adequately supported to use the information sources effectively are certain to be issues for every type of organisation in the next few years. By initiating discussions and working on a profession-wide basis, the implications of this for information professionals and others will be more clearly defined. NLS requires new collaborations and new ways of thinking. The major challenge for the information profession is to assume a leading role and to help determine the way information support in the networked environment develops.

This issue of Education for Information explores the scope and potential of NLS through the perspectives of a number of papers based on presentations at the $1 s t$ 
International Symposium on Networked Learner Support at the University of Sheffield in June 1996 [4]. There are already numerous examples across the UK and internationally of innovative, network-based approaches to the provision of learner support, and there is a need to share experience and ideas for developing the practice more widely. It was with this in mind that the idea for the Symposium emerged. Our aim was to offer a forum for exchanging information on current initiatives in NLS and for exploring the various learning, organisational and professional issues which arise. In the course of the two days a number of key issues were discussed, around the following questions:

- How can the interactive potential of the networks best be exploited to deliver "just-in-time" campus or distance support, bearing in mind highly diversified user groups and curriculum models?

- Which technologies offer most promise to meet different needs?

- What demands and opportunities do new curriculum initiatives in networked learning create for information support?

- What are the advantages and drawbacks of adopting computer-mediated approaches to learner support, and how do these fit with more traditional forms of user education, information skills training and other types of help?

- How is the role of learner support professionals altered in taking it onto the networks, and what are the professional development and training needs for it?

- How should responsibility for the provision of support be organised, and what new collaborations between professionals might this entail, especially between IT and library colleagues?

- How can the cultural change required to take learner support services and practice into the networked environment be managed, and, in turn, how can these services function as agents of culture change within their institutions?

- What are the NLS resourcing issues for the services involved?

The Symposium brought together over sixty people with a range of perspectives on NLS - librarians, IT specialists, lecturers and researchers in LIS, and others involved in teaching/learning support roles, including distance learning. The interdisciplinary mix was fruitful, and we hope to continue to develop that aspect of the Symposium for future events.

\section{The papers in this volume}

We begin with a paper by the NetLinkS team at Sheffield which discusses the project and current trends in NLS in UK higher education. NetLinkS is funded by the Joint Information Systems Committee of the Higher Education Funding Council for England (Electronic Libraries Programme) and has been gathering information on many NLS issues over the past year. The second phase of the project aims to establish a networked professional development community for NLS. 
A key feature of NLS is that it often calls for close collaboration between information and technology specialists. Ellen Chamberlain and Miriam Mitchell describe the benefits of bringing together library and IT expertise in order to develop an Internet-based training course for library staff. Their course is aimed at participants world-wide, but the listserv and world wide web (WWW) curriculum models they adopt could also be applied locally.

User education and information skills training is central to NLS. Gunilla Thomasson and Nancy Fjällbrant present the WWW-based EDUCATE programs, developed as a European Union initiative. These are user-education courses in two subject areas at present which are designed for a variety of uses both within the classroom or library, or at a distance for self-instruction.

The support of networked learners requires careful planning and Joan Carty, Isobel Stark, Robert van der Swan and Nicky Whitsted set out the issues they are tackling in planning a strategy for networked information support to distance learners at the Open University. The strategy includes the use of computer-mediated conferencing, structured access to the Web and electronic contact with the library help desk.

Clive Cochrane's paper explores the potential of videoconferencing in teaching and learning in higher education, particularly within the library and information field, and suggests that in the future desktop videoconferencing may become a viable medium for end-user help and training from the library.

When planning a curriculum based around networked learning, academics need to work in partnership with information professionals to ensure that learner support issues are considered. Kathy Buckner and Elizabeth Davenport describe the curriculum design for an undergraduate course in information management which is to use networked, case-based learning methods. They raise a wide range of management issues associated with the development and delivery of learning resources for such a course, and include discussion of the relationship between the academic department and support services.

Finally, Graham Walton, Joan Day and Catherine Edwards explore the perceptions of library professionals about possible role changes in the networked environment, identifying lack of awareness of the wider implications of developments in networked learning, and fears of losing professional "control" as some of the potential barriers to cultural change within the profession.

We welcome feedback on any of the papers included in this issue and we are always interested to hear about new developments in NLS. If you have any comments or examples of NLS practice taking place in your own institution, please do contact us.

\section{References}

[1] Joint Funding Councils' Libraries Review Group. Report. Bristol: Higher Education Funding Council for England, 1993. 
[2] John Fielden Consultancy. Supporting expansion: a report on human resource management in academic libraries, for the Joint Funding Councils' Libraries Review Group. Bristol: Higher Education Funding Council for England, 1993.

[3] S.P. Fowell and P. Levy. Developing a new professional practice: a model for networked learner support in higher education. Journal of Documentation 51 (3) (1995) 271-280.

[4] 1st International Symposium on Networked Learner Support: http://www.shef.ac.uk/ np/ nlssym.html

Sue Fowell

Institute of Professional Education (IPACE)

Unisearch

The University of New South Wales

NSW 2033

Australia

Email: s.fowell@unsw.edu.au

Philippa Levy

Department of Information Studies

The University of Sheffield

Western Bank

Sheffield S10 2TN

UK

Email: p.levy@sheffield.ac.uk 